entreCaminos, v.1, jul-dez 2015

\title{
O sentimento do fantástico em Bestiário, de Julio Cortázar
}

\section{Gisele Novaes Frighetto}

\section{RESUMO}

Investigamos neste trabalho o sentimento do fantástico na contística de Julio Cortázar, por meio da análise do conto Bestiário. Além da exegese do conto mencionado, verificamos como nele percebemos aspectos exemplares da contística do autor, a qual manifesta uma percepção fragmentária e simbólica da vida cotidiana, na qual irrompem com naturalidade acontecimentos insólitos, o que fez com que se caracterizasse a produção do autor sob a denominação "realismo fantástico".

\section{Introdução}

Publicado em 1951, Bestiário foi o primeiro livro de contos de Julio Cortázar. Os oito contos desse livro são exemplares da poética e da contística do autor, as quais, de forma geral, manifestam um investimento meticuloso na composição da forma conto e na narração de acontecimentos insólitos em meio ao cotidiano, o que fez com que se caracterizasse a produção do autor sob a denominação "realismo fantástico".

O enfoque deste trabalho centra-se na contribuição de Cortázar para o gênero fantástico que, para Todorov (1975), tivera seu auge entre os séculos XVIII e XIX e apresentava, no século seguinte, uma diluição da hesitação como seu princípio fundamental. A surpresa cede lugar, no modernismo, a uma percepção cotidiana do evento extraordinário, fazendo com que o fantástico seja em Cortázar, sobretudo, um sentimento que depende fundamentalmente da percepção do escritor e do leitor.

Propõe-se aqui investigar o sentimento do fantástico por meio da análise do conto-título Bestiário. Iniciaremos com uma breve análise do conto em questão para, 
entreCaminos, v.1, jul-dez 2015

em seguida, nele entrevermos as implicações para uma particular concepção do fantástico na literatura.

\section{O alegórico, o onírico e o humano}

O título, Bestiário, também nomeia todo o livro de Cortázar e dá-nos o sentido imediato de "fauna humana" não só ao texto em questão, mas ao painel humano criado pelo autor na coletânea de narrativas breves.

O conto propriamente dito narra a visita de uma menina, Isabel, aos reclusos e misteriosos Funes. Ela vai passar uma temporada de verão em Mar Del Plata na espaçosa e lúgubre casa da família,composta pelos irmãos Rema, Nenê e Luís e pelo filho deste último, o menino Nino (niño, no espanhol).Além da apreensão que a viagem a um ambiente desconhecido causa na menina, anuncia-se o aspecto extraordinário que envolve a família: um tigre mora na casa dos Funes.

A tensão apresentada no início intensifica-se no decorrer do enredo, com a chegada de Isabel à casa de cômodos interditados pela presença do tigre, os experimentos com animais, o assédio de Nenê a Rema, as agressões perpetradas por ele, por fim, o ataque do tigre a Nenê, provocado pela mentira de Isabel. O enredo é construído de forma a haver convergência de duas linhas de tensão, existentes na estranha relação entre humanos e animais e na interação conflituosa entre os membros da família.

Palco da narrativa fatalista das desavenças entre os Funes, a casa da família é simultaneamente o espaço do lúdico e do maravilhoso, impressão causada pela existência de elementos alegóricos e pela própria construção formal da narrativa.

Os brinquedos das crianças com plantas e animais como formigas, gafanhotos e caracóis são empresas científicas, de observação, estudo e catalogação dos seres. Esses animais, juntamente com o tigre, são seres simbólicos e representam qualidades humanas como o labor e a tenacidade (formigas), a observação (o gafanhoto), a malícia (os caracóis), as quais estão relacionadas aos personagens e aos temas da narrativa. 
Esta última é marcada pela imprecisão de um narrador observador cujo relato mimetiza a perspectiva fragmentária de uma menina, cuja voz se faz ouvir em primeira pessoa nos trechos entrecortados de sua correspondência com a mãe. A fragmentação e a aderência do narrador ao ponto de vista de uma personagem imatura implicam a ocultação de eventos que seriam facilmente percebidos por um personagem adulto, o que intensifica a atmosfera de mistério.

Isabel se aproximou para olhar os caracóis, e Luís, esperando que acendesse o seu cigarro como de hábito, viu-a distraída, estudando os caracóis que começavam a aparecer e a movimentar-se devagarinho, olhando rápido para Rema, mas desviando o olhar dela como uma rajada, e obcecada pelos caracóis, tanto que não se mexeu ao primeiro grito de Nenê [...]. (CORTÁZAR, 1971, p. 144)

Conforme Arrigucci Jr. (2003), a literatura de Cortázar nos remete à tradição do onírico e de sondagem do inconsciente que desemboca no Dadaísmo e no Surrealismo. Com relação a este último, do qual o escritor foi admirador e crítico, a escritura associa-se pela criação de imagens superpostas e pela fragmentação discursiva. Esses procedimentos correspondem a um aumento da ambiguidade, à abertura das possibilidades interpretativas e à informação estética da mensagem. As imagens dos contos são figuras cortazarianas nas quais "[...] uma multiplicidade de elementos heterogêneos, para além do tempo e do espaço, se cristalizaria numa revelação da realidade." (ARRIGUCCI JR., 2003, p. 85).

Em Bestiário, essa revelação consiste na percepção naturalizada do estranho e do irracional, dotados de sentido simbólico. A ampla e lúgubre casa dos Funes é uma das metáforas do sistema arquitetado por Cortázar,em cuja contística, segundo Passos (1986), comumente a casa se caracteriza como um território onde se estabelece o jogo entre o familiar e o estranho, a rotina prosaica e a inesperada ruptura. "Em todas as coletâneas publicadas por Julio Cortázar, destaca-se sempre uma narrativa em que o trabalho marcante e perturbador da metáfora de um espaço tomado por presenças estranhas acaba por inquietar personagens e/ou leitor." (PASSOS, 1986, p. 9)

Semelhantemente ao conto Casa Tomada, o inquietante tigre habita o espaço mais íntimo das personagens, dividido entre o interdito e o lugar onde se poderia circular e viver. Tornada, assim, espaço de cerceamento e controle, a casa dos Funes 
entreCaminos, v.1, jul-dez 2015

representa a intimidade familiar. Não se enxerga o tigre, apenas sabe-se da sua presença por uma rede de cooperação entre os membros da família e empregados interrompida por Isabel, por fim.

Oculto pelas paredes, o tigre pode significar a ferocidade oculta, manifesta no desejo sexual e na violência. Os Funes são seres aprisionados que reprimem suas paixões enquanto paradoxalmente jantam na "sala de cristais", exceto a outra "fera"dominante do conto, Nenê.

Nenê, cujo nome alude à imaturidade e egocentrismo do personagem, é um homem malicioso, irascível, violento. É sugerida, pelos olhos de Isabel, uma relação incestuosa entre ele e Rema. "[...] Rema que lhe levava o café e êle que pegava a xícara equivocando-se, tão desajeitado que apertou os dedos de Rema ao pegar a xícara. Isabel vira da sala de jantar que Rema puxava a mão e Nenê mal evitava que a xícara caísse e ria com a confusão." (CORTÁZAR, 1971,p. 132)

Em entrevista, Cortázar afirma que, em Bestiário, a escrita de certos contos possuiu efeito psicoterápico, ajudou-o a se livrar de neuroses e fobias. Uma dessas neuroses estaria relacionada à recorrência do tema do incesto, que apareceria no conto Bestiário. (BERMEJO, 2002, p. 34)

O estranhamento ultrapassa a convivência com um tigre de sentidos ambíguos e se transfere à percepção da natureza da relação entre irmãos, marcada pelo tabu do incesto. Sugere-se uma relação incestuosa também entre Rema e Luís: "Luís veio darIhes boa noite, murmurou algo sôbre a hora em que as crianças deviam ir para a cama, Rema sorriu ao beijá-lo." (CORTÁZAR, 1971, p. 140). Rema parece exercer o papel de mãe dos membros da família, e de esposa dos dois irmãos. Trata-se de uma mulher triste, frágil, oprimida por Nenê, acomodada à ordem das coisas. Luís é um personagem igualmente passivo, alheio no mais das vezes, "Luís foi o último a sair do seu quarto, contente como sempre ao meio-dia". (CORTÁZAR, 1971, p. 143)

O trabalho de catalogação das crianças assemelha-se à empresa do escritor, que enxerga de modo ampliado o real narrado e estrutura-o de maneira lógica. Segundo Cortázar, o trecho em que a personagem Isabel se levanta de noite para olhar o formigueiro é representativo da sua concepção lógica de criação literária. “Creio que, no fundo, já havia ali uma espécie de sistema aparentemente cego, os movimentos, o 
entreCaminos, v.1, jul-dez 2015

traçado feito pelas formigas... Há um certo desejo de criar estruturas." (BERMEJO, 2002, p. 78)

Embora a obra de Cortázar possa ser considerada um contundente libelo contra as limitações da racionalidade ocidental e uma questionadora feroz da precariedade do cientificismo castrador que a todos nos orienta, não se pode negar a presença de um raciocínio ordenador, geométrico, meticuloso na construção dessa mesma obra. (DAMAZIO, 2000, p. 15)

O enredo é meticulosamente estruturado em torno de uma unidade de efeito, a de estranhamento e destruição. A disfunção familiar prenuncia o desastre catalisado por Isabel, uma intrusa neste "formicário" (palavra-valise de formiga e aquário) ampliado para além da experimentação infantil. A associação entre as formigas e os Funes os caracteriza como seres aprisionados, afainosos e permanentemente em estado de guerra. São formigas os Funes, bem como os escritores que meticulosamente tecem seus formigueiros narrativos. Em perspectiva ampliada, o "formicário" pode representar não somente a tecelagem narrativa da dinâmica de coação familiar, mas também um microcosmo do labore luta humanos:

[...] as formigas pareciam furiosas e trabalhavam até de noite, cavando e removendo, com mil ordens e evoluções, alertado esfregar de antenas e patas, repentinos arranques de raiva ou veemência, concentrações e debandadas sem causa visível."(CORTÁZAR, 2003, p. 133)

De forma análoga, o título Bestiário alude aos personagens, ao trabalho literário e a uma concepção do humano. Uma das acepções da palavra, cujo radical encontra-se relativo a "besta" ou a "bestial", significa "compilação medieval de narrativas alegóricas e morais sobre animais fabulosos ou reais" ou "compilação de textos sobre animais". Em outra, "bestiário" quer dizer "área do circo romano onde se recolhiam as feras", ou, ainda, "indivíduo que combatia com feras no circo", "indivíduo condenado a ser devorado pelas feras na arena". (HOUAISS, 2012)

Tomando por base o conto, o título pode se referir, na primeira acepção, aos personagens como "humanos bestiais", tendo em mente que Bestiário também se 
trata de uma narrativa alegórica sobre animais. Na segunda, a "área onde se recolhem as feras" é o universo narrado, a casa dos Funes, onde se combate e se é devorado por feras. Em sentido abrangente, "bestiário" são as sociedades humanas, suas cidades, suas casas, espaços igualmente de lutas e coações.

No conto, formigas e tigres são bestiais como os Funes. Há feras que atacam, como Nenê, e feras acuadas, como Rema. Isabel, como um gafanhoto, é o animal observador, "É o único inseto que gira a cabeça." (CORTÁZAR, 1971, P. 140). Uma vez dentro do formicário, ela acaba por participar dos enfrentamentos, sendo o catalisador da explosão do conflito latente. A ruptura do laço de confiança pela menina, que terá como consequência o ataque e possível aniquilação de Nenê pelo tigre, institui a perda da inocência infantil. Afinal, dentro da menina Isabel também há o gérmen da violência, mesmo que direcionado para a extirpação do mal e realização da justiça.

A revelação do drama familiar e seu trágico desfecho dizem respeito, conforme reiterado, à natureza do humano e à sua realidade. Para Arrigucci Jr. (2003), a busca surrealista voltada para a revelação da realidade coincide com a poética cortazariana, a qual busca atingir essa revelação por meio da verdade da invenção de um universo do qual o insólito é parte integrante.

Se na narrativa fantástica, com sua oscilação entre real e irreal, é a própria ambiguidade na visão de mundo que se torna responsável pelo envolvimento do leitor, em outros textos cortazarianos é esse princípio formal básico para os surrealistas que leva o leitor a participar diretamente na estruturação da obra, montando os fragmentos, escolhendo os rumos e desdobramentos da construção. (ARRIGUCCI JR., 2003, p. 88)

Consideramos que há no conto Bestiário a existência do estranhamento e da tensão próprios da literatura fantástica, mas renovados, já que o extraordinário não causa hesitação aos personagens e possui sentido alegórico. Vejamos, pois, como o texto aqui analisado se articula a algumas considerações do escritor e a outras definições sobre o tema.

\section{O sentimento do fantástico}


Ao afirmar que "Quase todos os contos que escrevi pertencem ao gênero chamado fantástico por falta de nome melhor" (2006, p. 148), Cortázar anuncia os impasses envolvidos não só na definição da sua literatura, como do gênero no século $X X$. Entretanto, embora rejeite a denominação, empregou com frequência o termo "fantástico", elaborou e apresentou convicções próprias sobre ele. Na entrevista a Bermejo (2002), afirmou que, numa fase inicial de sua produção, preocupou-se menos com o conteúdo humano do que com os mecanismos do conto, no caso, do conto fantástico.

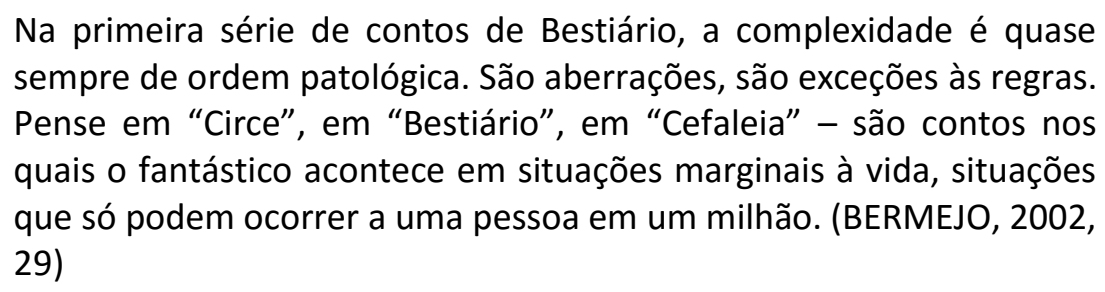

No conto Bestiário, o fantástico provém de uma "inquietante estranheza" (PASSOS, 1986, p. 10), fundamentada na relação das crianças com animais de certo modo repulsivos, no caso, as formigas, o gafanhoto e os caracóis - de sentido metafórico -, na existência do tigre e, principalmente, na aparente normalidade da convivência da família com o animal. "Uma casa enorme e no pior dos casos não se tinha de entrar em um cômodo, nunca mais de um, de modo que não se importavam." (CORTÁZAR, 1971, p. 129)

Para Cleusa Passos (1986), o conceito freudiano de "Unheimlich" representa o íntimo recalcado, o retorno de uma coisa familiar que deveria ter permanecido oculta. Os animais dos Funes representam sentimentos humanos que possuem reverberação nos personagens e nos próprios leitores, fazendo com que se atinja o "ponto vélico" a que se refere Cortázar em Do sentimento do fantástico, quando afirma que o fantástico ocorre quando há identificação entre os fantasmas dos personagens e do leitor.

[...] o verdadeiro fantástico não reside tanto nas estreitas circunstâncias narradas, mas na sua ressonância de pulsação, de 
palpitar surpreendente de um coração alheio ao nosso, de uma ordem que nos pode usar a qualquer momento para um dos seus mosaicos, arrancando-nos da rotina para nos pôr um lápis ou um cinzel na mão. (CORTÁZAR, 2006a, p. 179)

O sentimento do fantástico, em Cortázar, depende fundamentalmente da percepção do escritor e do leitor, que enxergam e aceitam a existência do insólito. É importante notar que, para Cortázar, o real está aberto ao irreal, como parte constituinte do próprio sistema. Isto difere da tradicional acepção de Todorov (1975), calcada na distinção entre real e irreal ficcional, já que em Cortázar a hesitação fundamental dá lugar à "mais absoluta suspensão da incredulidade".

Todorov, em seu estudo Introdução à Literatura Fantástica, define o fantástico como acontecimento que não pode ser explicado pelas leis naturais e que, portanto, seria integrante de uma realidade regida por leis desconhecidas. Esse acontecimento gera uma hesitação nos personagens e no leitor, em acreditar ou não na existência do evento extraordinário. A dúvida entre o real e o ilusório ou imaginário, o natural e o sobrenatural, é condição do fantástico para Todorov: "[...] o fantástico se fundamenta essencialmente numa hesitação do leitor - um leitor que se identifica com a personagem principal - quanto à natureza de um acontecimento estranho." (TODOROV, 1975, p. 166)

Se houver a aceitação do sobrenatural ou a sua explicação racional, suspendese a hesitação e não estaríamos mais diante do fantástico, mas de outros gêneros limítrofes. Se há o "sobrenatural explicado", tem-se o estranho; se a decisão recai sobre novas leis da natureza que admitem o fenômeno, tem-se o maravilhoso. (TODOROV, 1975, 48)

Por sua vez, a linguagem poética ou alegórica, que "implica na existência de pelo menos dois sentidos para as mesmas palavras" (TODOROV, 1975, p. 71) também obstruiria a existência do fantástico, cuja condição importante seria pertencer ao domínio da fiç̧ão e do sentido literal. O duplo sentido da alegoria esvaziaria o estranhamento e, portanto, a hesitação. Seriam, pois, as condições do fantástico:

Primeiro, é preciso que o texto obrigue o leitor a considerar o mundo das personagens como um mundo de criaturas vivas e a hesitar entre uma explicação natural e uma explicação sobrenatural dos 
acontecimentos evocados. A seguir, esta hesitação pode ser igualmente experimentada por uma personagem; desta forma o papel do leitor é, por assim dizer, confiado a uma personagem e ao mesmo tempo a hesitação encontra-se representada, torna-se um dos temas da obra; no caso de uma leitora ingênua, o leitor real se identifica com a personagem. Enfim, é importante que o leitor adote uma certa atitude para com o texto: ele recusará tanto a interpretação alegórica quanto a interpretação "poética". (TODOROV, 1975, p. 39)

Evidentemente, para o nosso objeto as considerações de Todorov se revelam problemáticas, já que o fantástico em Cortázar dispensa a hesitação e admite o maravilhoso e o alegórico. Fundamenta-se no estranhamento e na aceitação do insólito como possibilidade da própria realidade. De fato, o escritor chega a rechaçar a empresa de Todorov, já que, para ele, o autor não consegue por fim explicar o sentimento de fantástico. "Acontece com o fantástico a mesma coisa que acontece com a poesia, que, segundo o humorista, é 'o que resta depois de definida a poesia'”. (BERMEJO, 2002, P. 36)

Diante disso, afirma que o possível é a tentativa de buscar uma definição satisfatória para pessoas comuns, já que, para ele, o fantástico se trata de algo que pode acontecer em plena realidade cotidiana. "Trata-se de algo absolutamente excepcional, concordo, mas que não tem por que ser diferente, em suas manifestações, da realidade que nos envolve. O fantástico pode acontecer sem que haja uma mudança espetacular das coisas." (BERMEJO, 2002, p. 37)

Contudo, deve-se considerar que Todorov busca categorizar o fantástico tradicional, quese encerraria com o século XIX, sendo as narrativas de Maupassant as últimas do gênero. As considerações de Cortázar sobre o tema se aproximariam do que Todorov chama de uma "narrativa do sobrenatural", forma adquirida pelo fantástico no século XXquepossui como diferença substancial a aceitação do sobrenatural, tratado com naturalidade. Tal como ocorre em A metamorfose, de Kafka, "[...] onde a coisa mais supreendente é precisamente a ausência de surpresa diante deste acontecimento inaudito [...]" (TODOROV, 1975, p. 177).

A ausência de hesitação não implica, porém, na existência de um mundo regido por leis consideradas extraordinárias, como ocorre com o maravilhoso. Todorov retoma o texto de Sartre, Aminadab ou du fantastique consideré comme um langage 
para mostrar como o extraordinário pode integrar-se ao ordinário cotidiano,na medida em que este último permita ser encarado como insólito.

Para Sartre, a ausência de hesitação não configura outras formas narrativas, mas a sobrevivência do fantástico, modificado. Nas narrativas fantásticas de Kafka e Blanchot não seria necessário pintar o extraordinário - fadas ou entes mágicos - para alcançar o fantástico. O fantástico não está no extraordinário, mas no mundo e na natureza que a ele obedecem. Descobre-se o incomum no próprio homem, realizando um retorno ao humano no fantástico. "Seulement, pour trouver place dans I'humanisme contemporain, le fantastique va se domestiquer comme les autres, renoncer à la exploration des realités transcendantes, se résigner à transcrire la condition humaine. ${ }^{1 " \prime}$ (SARTRE, 1947, p. 117)

Modificado, o fantástico tem continuidade ao representar a irrupção da irracionalidade encarada não mais como um corpo estranho, à maneira das crenças cientificistas ou racionalistas, mas como integrante do universo humano nas sociedades modernas.

Ceux-ci, catalogues, classes, figés, inutiles, cessent de faire peur ou de Donner le vertige: à Kafka n'était qu'une étape ; à travers lui, comme à travers Hoffmann, comme à travers Poe, Carroll et les surréalistes, le fantastique poursuit le progrès continu que doit, à la limite, le rejoindre à ce qu'il a toujours été. ${ }^{2}$ (SARTRE, 1947, p. 132)

Em Bestiário, o fantástico envolve a aceitação do sobrenatural e provoca, também, uma abertura da percepção ao maravilhoso e ao simbólico como elementos constituintes da realidade cotidiana e da própria natureza humana. Para o escritor, se nos abríssemos ao fantástico, todos nós os perceberíamos e da mesma forma, veríamos a nós mesmos como fantasmas, e o mundo como insólito. "Os únicos que crêem verdadeiramente nos fantasmas são os próprios fantasmas [...]". (CORTÁZAR, 2006a, p. 179)

\footnotetext{
${ }^{1}$ Portanto, por ter lugar no humanismo contemporâneo, o fantástico domesticar-se-á como os outros e renunciará à exploração das realidades transcendentes, resignando-se a transcrever a condição humana. Tradução minha.

${ }^{2}$ Estes catálogos de classes congeladas, inúteis, cessam de causar medo ou vertigem: Kafka é somente uma etapa, através dele como através de Hoffman, como através de Poe, Carroll e os surrealistas, o fantástico persegue o progresso contínuo que deve, no limite, trazê-lo àquilo que ele sempre foi. Tradução minha.
} 
entreCaminos, v.1, jul-dez 2015

Não à toa, a protagonista de Bestiário é uma criança. A aceitação do absurdo é percebida por Cortázar como própria de uma percepção infantil, que nada põe em dúvida, aberta a uma "ordem mais secreta e menos comunicável” (2006b, p. 148). Mesmo que oculta ou irracional, essa ordem pode ser reveladora não só de uma realidade outra, mas das próprias verdades humanas.

\section{Conclusão}

Na narrativa de Bestiário, o estranhamento provém da convivência pacífica, até um dado momento, de humanos com um animal feroz. Não é difícil relacionar a concepção de mundo do conto a uma concepção do humano no mundo de forma mais ampla, onde, acuados ou feras, convivemos prestes a enfrentar-nos, devorar-nos ou sermos devorados. Em outro sentido, o conto alude a uma concepção psicanalítica do humano, cujo inconsciente abriga a ferocidade que habita em nós.

O fantástico em Cortázar seria a indicação de que uma percepção paradoxal, do ilógico na lógica, não constitui uma negação do real, mas uma maneira mais ampliada de percebê-lo e, talvez, modificá-lo: “[...] em nossos tempos, [a realidade] passou a ser um grande campo de batalha. Em que plano, nós, escritores, podemos responder a ela? Para mim, no plano que considero mais importante: o da tentativa de modificála." (BERMEJO, 2002, p. 111).

\section{Artigo submetido em 05 de março de 2014.}

Artigo aceito para publicação em 08 de janeiro de 2015.

\section{Referências}

ARRIGUCCI JR., Davi. O escorpião encalacrado: a poética da destruição em Julio Cortázar. São Paulo: Companhia das Letras, 2003.

BERMEJO, Ernesto G. Conversas com Cortázar. Rio de Janeiro: Jorge Zahar, 2002. 
entreCaminos, v.1, jul-dez 2015

CORTÁZAR, J. Bestiário. 2a ed. Trad. De Remy Gorga Filho. Rio de Janeiro: Editora Civilização e Cultura, 1971.

CORTÁZAR, Julio. Alguns aspectos do conto. In: Valise de cronópio. São Paulo: Perspectiva, 2006b. p. $147-163$.

CORTÁZAR, Julio. Do sentimento do fantástico. In: Valise de cronópio. São Paulo: Perspectiva, 2006. p. 175-179.

DAMAZIO, Reynaldo. O poliedro Cortázar. Revista Cult. Out. 2000. p. 15-18.

DICIONÁRIO HOUAISS. Disponível em: http://houaiss.uol.com.br/busca.jhtm?verbete=besti\%E1rio\&cod=31288. Acesso em 28.06.2012.

PASSOS, Cleusa R. P. O outro modo de mirar:uma leitura dos contos de Julio Cortázar. São Paulo: Martins Fontes, 1986.

SARTRE, Jean-Paul. Aminadab ou du fantastique consideré comme um langage. In: . Situations I: essais critiques. Paris: Gallimard, 1947. p. 113-132.

SOSNOWSKI, Saúl. A cosmopista do risco. Revista Cult. Out. 2000. p. 20-25.

TODOROV, T. Introdução à literatura fantástica. São Paulo: Perspectiva, 1975. 